\title{
Anthocyanin pigments in strawberry
}

\author{
Fátima Lopes da Silva ${ }^{1}$, María Teresa Escribano-Bailón, José Joaquín Pérez Alonso, \\ Julián C. Rivas-Gonzalo, Celestino Santos-Buelga*
}

Facultad de Farmacia, Laboratorio de Nutrición y Bromatología, Universidad de Salamanca, Campus Miguel de Unamuno s/n, E-37007 Salamanca, Spain

Received 3 November 2004; received in revised form 29 September 2005; accepted 29 September 2005

\begin{abstract}
The anthocyanin composition was analysed in strawberry fruits from five different cultivars (cv. Eris, Oso Grande, Carisma, Tudnew and Camarosa). Twenty-five defined anthocyanin pigments were detected, most of them containing Pelargonidin (Pg) as aglycone; some cyanidin (Cy) derivatives were also found. Glucose and rutinose were the usual substituting sugars, although arabinose and rhamnose were also tentatively identified; some minor anthocyanins showed acylation with aliphatic acids. A relevant aspect was the detection of anthocyanin-derived pigments, namely 5-carboxypyranopelargonidin-3-glucoside and four condensed pigments containing $\mathrm{C}-\mathrm{C}$ linked anthocyanin $(\mathrm{Pg})$ and flavanol (catechin and afzelechin) residues. Total anthocyanin content ranged between $200 \mathrm{and} 600 \mathrm{mg} \mathrm{kg}{ }^{-1}$, with Pg 3-gluc constituting 77-90\% of the anthocyanins in the strawberry extracts followed by Pg 3-rut (6-11\%) and Cy 3-gluc (3-10\%). A notable variability was found among the anthocyanin concentrations in samples of a same variety and harvest, indicating a strongly influence of the degree of maturity, edaphic-climatic factors and post-harvest storage.
\end{abstract}

(C) 2005 Swiss Society of Food Science and Technology. Published by Elsevier Ltd. All rights reserved.

Keywords: Anthocyanins; Strawberry; Pelargonidin; Cyanidin; Anthocyanin-derived pigments

\section{Introduction}

Strawberry fruits (Fragaria $\times$ ananassa Duch.) have been shown to possess high in vitro antioxidant activity that has been positively correlated with the content of polyphenolic compounds and, specifically, anthocyanins, the type of polyphenols quantitatively most important in strawberry (Heinonen, Meyer, \& Frankel, 1998; Wang \& Jiao, 2000; Wang \& Lin, 2000). The anthocyanin composition in strawberry has been the object of various studies, but is still not fully characterized regarding minor pigments. Strawberry anthocyanins derive from pelargonidin $(\mathrm{Pg})$ and cyanidin (Cy) aglycones (Fig. 1a) (Mazza \& Miniati, 1993). The major anthocyanin in the fruits is $\mathrm{Pg} 3$-glucoside (Pg 3gluc), as firstly identified by Robinson and Robinson (1931). In smaller proportions the presence of $\mathrm{Cy} 3-$ glucoside (Cy 3-gluc) seems also constant in all varieties

\footnotetext{
*Corresponding author. Fax: + 34923294515.

E-mail address: csb@usal.es (C. Santos-Buelga).

${ }^{1}$ Current address: Escola Superior Agrária de Bragança, Campus de Santa Apolónia, P-5301-855 Bragança, Portugal.
}

(Bridle \& Garcia-Viguera, 1997; Hong \& Wrolstad, 1990a; Lukton, Chichester, \& MacKiney, 1955) and Pg 3-rutinoside (Pg 3-rut) is also commonly found (Bakker, Bridle, \& Bellworthy, 1994; Co \& Markakis, 1968; Hong \& Wrolstad, 1990b). Furthermore, Pg 3-arabinoside (Fiorini, 1995; Goiffon, Mouly, \& Gaydou, 1999) and Cy 3rutinoside (Bridle \& Garcia-Viguera, 1997) have been cited in some strawberry cultivars, as well as various acylated anthocyanins. In particular, Pg 3-(6-malonylglucoside) was unequivocally identified by Tamura, Takada and Yoshida (1995) and indicated as one of the main pigments in several Japanese cultivars, comprising 5-30\% of total anthocyanin content (Tamura et al., 1995; Yoshida, Koyama, \& Tamura, 2002). Other acylated anthocyanins also reported in strawberry are Pg 3-acetylglucoside (Hong \& Wrolstad, 1990b) and Pg succinylglucoside (Bakker et al., 1994).

In a previous study by our group (Lopes-da-Silva, de Pascual-Teresa, Rivas-Gonzalo, \& Santos-Buelga, 2002), the anthocyanin composition in strawberries of cv. Camarosa was analysed using electrospray ionization mass spectrometry ESI-MS coupled to HPLC. In addition to the major anthocyanins (i.e. Pg 3-gluc, Pg 3-rut and Cy 3-gluc) 
<smiles></smiles>

(a)<smiles>O=C(O)C1=CC2=C(OC3OC(CO)[C@@H](CO)C(O)C3O)C(c3ccc(O)cc3)=[O+]c3cc(O)cc(c31)O2</smiles>

(b)

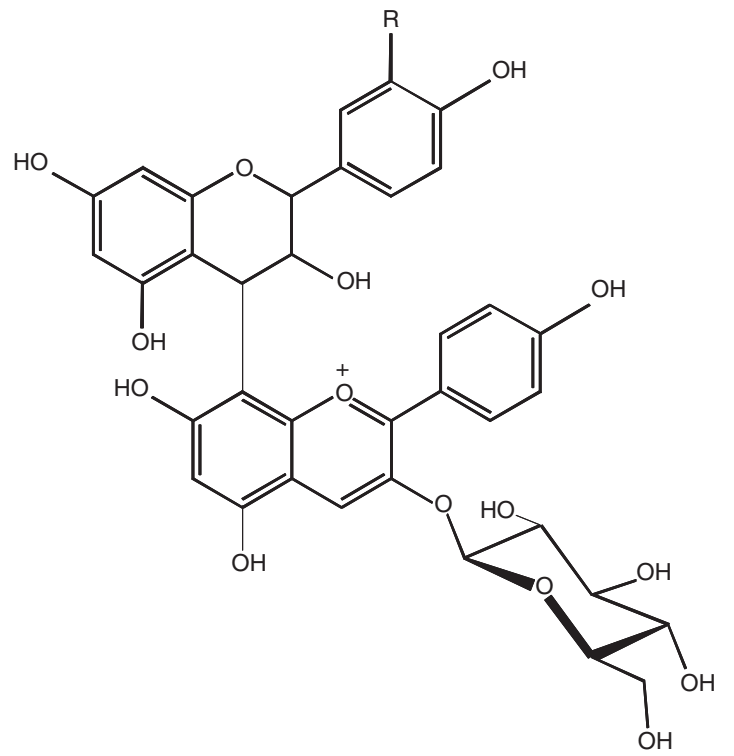

(Epi)afzelechin-(4,8)-pelargonidin 3-glucoside, $\mathrm{R}=\mathrm{H}$

(Epi)catechin-(4,8)-pelargonidin 3-glucoside, $\mathrm{R}=\mathrm{OH}$

Fig. 1. Structures of pigments found in strawberry. (a) Anthocyanin aglycones; (b) 5-carboxypyranopelargonidin 3-glucoside (Andersen et al., 2004); and (c) anthocyanin-flavanol condensed pigments (Fossen et al., 2004).

12 minor anthocyanins were detected although identity could be only assigned to five of them as Pg 3-acetylglucoside, Cy 3-rutinoside, Pg 3-malylglucoside, Pg diglucoside, and Cy 3-malonylglucosyl-5-glucoside, the three latter not being described previously in strawberry.

Quite recently, small amounts of some anthocyaninrelated pigments have also been detected and identified in strawberries, including 5-carboxypyranopelargonidin 3glucoside (Fig. 1b) (Andersen, Fossen, Torskangerpoll, Fossen, \& Hauge, 2004) and four purple anthocyaninflavanol complexes consisting of pelargonidin 3-glucoside $\mathrm{C}-\mathrm{C}$ linked to (epi)catechin and (epi)afzelechin moieties (Fig. 1c) (Fossen, Rayyan, \& Andersen, 2004). That was the first evidence of the occurrence in a natural plant source of this type of condensed pigments, whose formation was associated to reactions taking place during maturation and ageing of red wines (Jurd, 1969; Salas et al., 2004; Somers, 1971; Vivar-Quintana, Santos-Buelga, Francia-Aricha, \& Rivas-Gonzalo, 1999). Further evidence about the presence of anthocyanin-flavanol condensed pigments in strawberry fruits and other plants has also been recently contributed by our group (González-Paramás et al., 2005).

The aim of the present work is to update the knowledge about strawberry anthocyanins, for which the anthocyanin composition, qualitative and quantitative, has been analysed in strawberry fruits from five different cultivars, using HPLC coupled to diode array and MS detection.

\section{Materials and methods}

\subsection{Samples}

Strawberries (Fragaria $\times$ ananassa Duch.) from five selected cultivars (cv. Camarosa, Carisma, Eris, Oso Grande and Tudnew) grown at an experimental station at Instituto de la Grasa-CSIC in Seville (Spain) and picked at commercial maturity were collected in years 2001 and 
2002. After harvest, fruits were washed in water and frozen and stored at $-35^{\circ} \mathrm{C}$ until analysis.

\subsection{Sample preparation}

Frozen strawberries $(40-50 \mathrm{~g})$ were homogenized in $\mathrm{MeOH}$ containing $0.1 \% \mathrm{HCl}$, kept overnight $(\sim 14 \mathrm{~h})$ at $3-5{ }^{\circ} \mathrm{C}$ and later filtered through a Büchner funnel under vacuum. The solid residue was exhaustively washed with methanol and the filtrates obtained were centrifuged $\left(4000 \mathrm{~g}, \quad 15 \mathrm{~min}, 2^{\circ} \mathrm{C}\right.$ ) and the solid residue further submitted to the same process the number of times necessary to complete extraction of the colour. Hydroalcoholic phases were combined, water was added, the supernatant was concentrated under vacuum in a rotary evaporator at $<30^{\circ} \mathrm{C}$ to total evaporation of the methanol; the aqueous extract obtained was washed with $n$-hexane to remove liposoluble substances. An aliquot $(2 \mathrm{ml})$ of the aqueous phase was carefully deposited onto a C-18 SepPak ${ }^{\circledR}$ Vac 3cc cartridge (Waters); sugars and more polar substances were removed by passing $15 \mathrm{ml}$ of ultrapure water and anthocyanin pigments further eluted with $5 \mathrm{ml}$ of $\mathrm{MeOH}: 0.1 \%$ TFA (95:5). The methanolic extract was concentrated under vacuum in a rotary evaporator at $<30{ }^{\circ} \mathrm{C}$ after adding some water. The aqueous extract was collected, its volume completed to $2 \mathrm{ml}$ with ultrapure water and filtered through a $0.45-\mu \mathrm{m}$ membrane filter for HPLC analysis. For each strawberry variety and year of harvest, three independent extracts were prepared that were purified and analysed separately.

\subsection{HPLC-DAS-MS analyses}

Analyses were performed in a Hewlett-Packard 1100 series liquid chromatograph. Separation was achieved on a $5-\mu \mathrm{m} \mathrm{AQUA}^{\circledR} \mathrm{C} 18150 \mathrm{~mm} \times 4.6 \mathrm{~mm}$ column (Phenomenex ${ }^{\circledR}$, Torrance, CA) thermostatted at $35^{\circ} \mathrm{C}$. Solvents used were: (A) $0.1 \%$ trifluoroacetic acid in water, and (B) HPLC-grade acetonitrile, establishing the following gradient: isocratic $10 \% \mathrm{~B}$ for $5 \mathrm{~min}, 10-15 \% \mathrm{~B}$ over $15 \mathrm{~min}$, isocratic $15 \% \mathrm{~B}$ for $5 \mathrm{~min}, 15-18 \% \mathrm{~B}$ over $5 \mathrm{~min}$, and

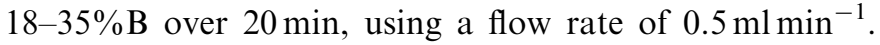
Double on-line detection was carried out in a diode array spectrophotometer (DAS), using $520 \mathrm{~nm}$ as the preferred wavelength, and in a mass spectrometer (MS) connected to the HPLC system via the DAS cell outlet.

The mass spectrometer was a Finnigan LCQ (San Jose, CA) equipped with an ESI source and an ion trap mass analyser, which were controlled by the LCQ Xcalibur software. Nitrogen was used as both auxiliary and sheath gas at flow rates of 6 and $1.21 \mathrm{~min}^{-1}$, respectively. The capillary voltage was $4 \mathrm{~V}$ and the capillary temperature $195^{\circ} \mathrm{C}$. Spectra were recorded in positive ion mode between $\mathrm{m} / \mathrm{z} 150$ and 1500 . The MS detector was programmed to perform a series of three consecutive scans: a full scan, a zoom scan of the most abundant ion in the first scan and an MS-MS scan of the most abundant ion, using a normalized collision energy of $45 \%$.

\subsection{Quantification}

The three major anthocyanins in strawberry were quantified from the areas of their chromatographic peaks recorded at $520 \mathrm{~nm}$ by comparison with calibration curves obtained with external standards of $\mathrm{Cy} 3$-gluc (for cyanidin-based anthocyanins) and of $\mathrm{Pg} \mathrm{3-gluc} \mathrm{(for}$ pelargonidin-based anthocyanins). Strawberry extracts were analysed in triplicate.

\section{Results and discussion}

\subsection{Pigment identification}

In the different strawberry varieties analysed 25 anthocyanin pigments were detected for which suitable information concerning their UV-vis or mass spectral characteristics could be obtained. Fig. 2 shows the HPLC anthocyanin profiles in the samples of the five strawberry cultivars analysed (i.e. cv. Tudnew, Carisma, Camarosa, Eris and Oso Grande). Peak data obtained in the HPLCDAS-MS analyses (retention time in the HPLC system, $\lambda_{\max }$ in the visible region, molecular ion and main fragments observed in $\mathrm{MS}^{2}$ ) are summarized in Table 1, together with the strawberry varieties in which each peak was detected. In addition to the compounds indicated in that table, other very minor pigments were also detected although no good absorption or mass spectra could be obtained to allow speculation about their identity.

Pelargonidin shows a characteristic UV-vis spectrum shape with $\lambda_{\max }$ in the visible region at lower wavelengths (about $500 \mathrm{~nm}$ ) than other common anthocyanins and an additional maximum about $430 \mathrm{~nm}$ (Fig. 3). Based on it the peaks corresponding to Pg-derived anthocyanins could be easily assigned in the chromatograms. It is necessary to take into account that during gradient HPLC run a progressive bathochromic shift in the visible $\lambda_{\max }$ of the anthocyanin peaks is produced with the increase in the percentage of acetonitrile in the mobile phase (Hebrero, Santos-Buelga, \& Rivas-Gonzalo, 1988). Thus, $\lambda_{\max }$ of the peaks of the Pg-based anthocyanins vary from $500 \mathrm{~nm}$ (peak 6) to $508 \mathrm{~nm}$ (peak 23). The presence of $\mathrm{Pg}$ as anthocyanidin in those peaks was further confirmed by their mass spectra, which showed an $\mathrm{MS}^{2}$ signal at $\mathrm{m} / \mathrm{z}$ $[\mathrm{M}]^{+}$271. In addition, five peaks $(5,8,9,18$ and 24) were identified as $\mathrm{Cy}$ derivatives based on the presence of a signal at $m / z[\mathrm{M}]^{+} 287$ in their $\mathrm{MS}^{2}$ spectra. Mass spectral characteristics also allowed to assign five other peaks to anthocyanin-derived pigments as discussed below.

Major peaks in the HPLC chromatograms in all samples corresponded to Pg 3-gluc (peak 10), Pg 3-rut (peak 12) and Cy 3-gluc (peak 5). Besides them, compounds 1, 2, 3, 19 and 21 were also found in all the samples analysed. Peak 21 would correspond to Pg 3-acetylglucoside, as previously 

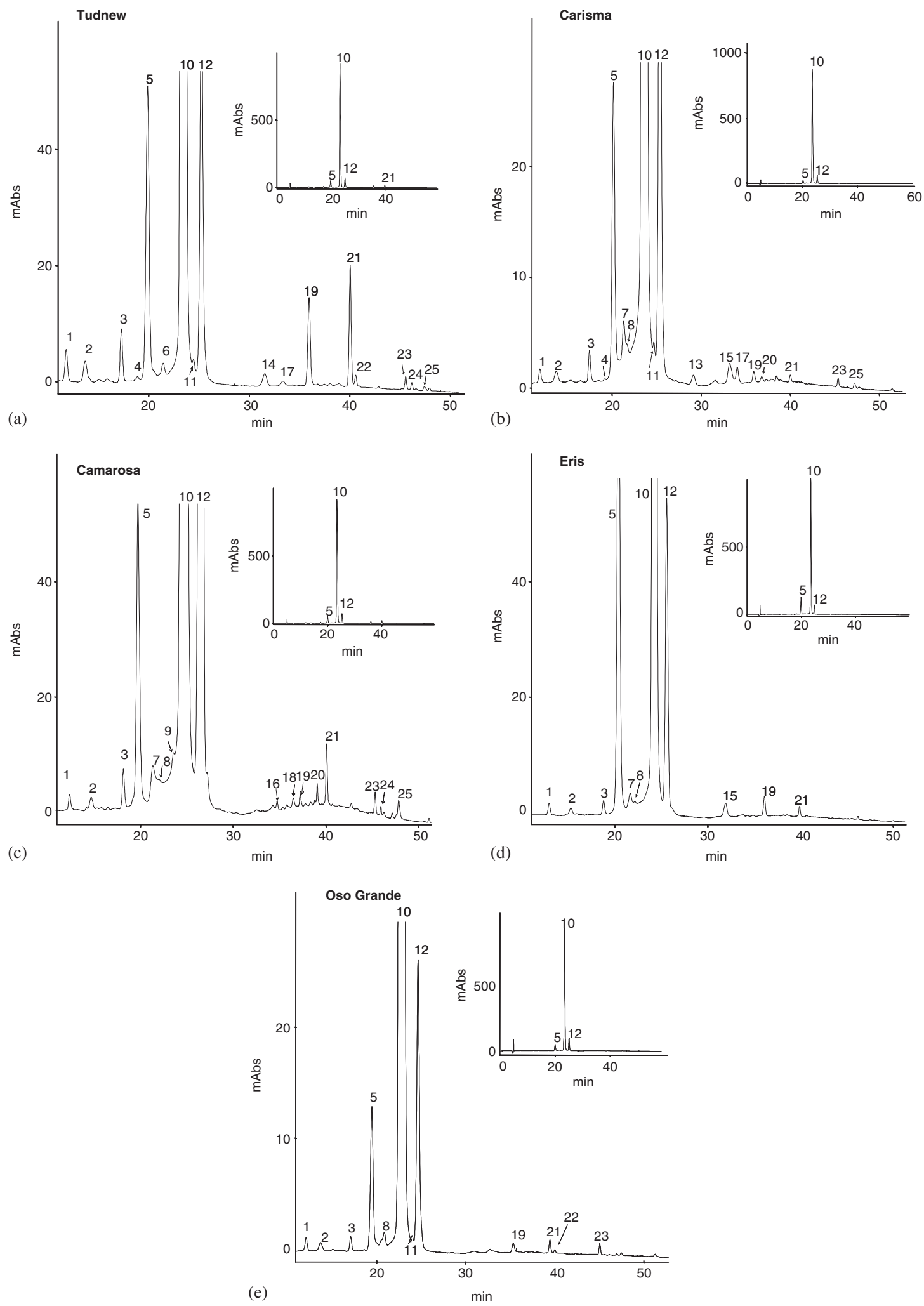

Fig. 2. Chromatograms (zoom) recorded at $520 \mathrm{~nm}$ showing the anthocyanin profiles of the strawberry samples. (a) cv. Tudnew; (b) cv. Carisma, (c) cv. Camarosa, (d) cv. Eris, (e) cv. Oso Grande. Full chromatogram is shown in the small window. See Table 1 for peak identification.

suggested (Lopes-da-Silva et al., 2002). Its presence in strawberry had also been indicated by Hong and Wrolstad (1990b). Peak 19 was relatively important in the samples of cv. Tudnew (Fig. 2a). Its UV-vis $\left(\lambda_{\max }\right.$ at $\left.504 \mathrm{~nm}\right)$ and mass spectra (molecular ion at $\mathrm{m} / z 519$ releasing a unique $\mathrm{MS}^{2}$ fragment at $\mathrm{m} / z 271$ corresponding to $\mathrm{Pg}$ ) allowed possible identity as $\mathrm{Pg}$ 3-malonylglucoside, previously identified in strawberry by Tamura et al. (1995). The equivalent Cy 
Table 1

Retention time (Rt), wavelengths of maximum absorption in the visible region $\left(\lambda_{\max }\right)$, mass spectral data, tentative identification of anthocyanin pigments and strawberry varieties in which they were detected

\begin{tabular}{|c|c|c|c|c|c|c|}
\hline Peak & Rt (min) & $\begin{array}{l}\lambda_{\max } \\
(\mathrm{nm})\end{array}$ & $\begin{array}{l}\text { Molecular ion } \\
{\left[\mathrm{M}^{+}\right](\mathrm{m} / \mathrm{z})}\end{array}$ & $\operatorname{MS}^{2}(m / z)$ & Tentative identification $^{\mathrm{a}}$ & Strawberry variety ${ }^{\mathrm{b}}$ \\
\hline 1 & 12.3 & 515 & 721 & $559,407,313,271$ & Catechin- $(4 \rightarrow 8)-P g$ 3-glucoside & $\mathrm{Ca}, \mathrm{Cr}, \mathrm{Er}, \mathrm{Os}, \mathrm{Tu}$ \\
\hline 2 & 14.0 & 517 & 721 & $559,407,313,271$ & Epicatechin-( $4 \rightarrow 8)$-Pg 3-glucoside & $\mathrm{Ca}, \mathrm{Cr}, \mathrm{Er}, \mathrm{Os}, \mathrm{Tu}$ \\
\hline 3 & 17.7 & 515 & 705 & $543,407,313,271$ & (Epi)afzelechin-(4 $\rightarrow$ 8)-Pg 3-glucoside & $\mathrm{Ca}, \mathrm{Cr}, \mathrm{Er}, \mathrm{Os}, \mathrm{Tu}$ \\
\hline 4 & 19.3 & 518 & 851 & $543,407,313,271$ & (Epi)afzelechin-(4 $\rightarrow$ 8)-Pg 3-rutinoside & $\mathrm{Ca}, \mathrm{Cr}, \mathrm{Tu}$ \\
\hline 5 & 20.3 & 515 & 449 & 287 & Cy 3-glucoside & $\mathrm{Ca}, \mathrm{Cr}, \mathrm{Er}, \mathrm{Os}, \mathrm{Tu}$ \\
\hline 6 & 21.5 & 500 & 433 & 271 & Pg-3-galactoside & $\mathrm{Ca}, \mathrm{Tu}$ \\
\hline 7 & 21.5 & 500 & 595 & 433,271 & Pg 3,5-diglucoside & $\mathrm{Ca}, \mathrm{Cr}, \mathrm{Er}, \mathrm{Os}$ \\
\hline 8 & 21.8 & 515 & 595 & 449,287 & Cy 3-rutinoside & $\mathrm{Ca}, \mathrm{Cr}, \mathrm{Er}, \mathrm{Os}$ \\
\hline 9 & 23.0 & 524 & 697 & $535,449,287$ & Cy 3-malonylglucosyl-5-glucoside & $\mathrm{Ca}$ \\
\hline 10 & 23.8 & 502 & 433 & 271 & Pg 3-glucoside & $\mathrm{Ca}, \mathrm{Cr}, \mathrm{Er}, \mathrm{Os}, \mathrm{Tu}$ \\
\hline 11 & 24.8 & 492 & 501 & 339 & 5-carboxypyranopelargonidin-3-glucoside & $\mathrm{Cr}, \mathrm{Os}, \mathrm{Tu}$ \\
\hline 12 & 25.5 & 503 & 579 & 433,271 & Pg 3-rutinoside & $\mathrm{Ca}, \mathrm{Cr}, \mathrm{Er}, \mathrm{Os}, \mathrm{Tu}$ \\
\hline 13 & 29.3 & 503 & 549 & 271 & Pg 3-malylglucoside & $\mathrm{Cr}$ \\
\hline 14 & 31.6 & 504 & 422 & 331 & Unknown & $\mathrm{Ca}, \mathrm{Er}, \mathrm{Tu}$ \\
\hline 15 & 32.6 & 503 & 607 & 271 & $\begin{array}{l}\text { Pg-dissacharide (hexose }+ \text { pentose) acylated } \\
\text { with acetic acid }\end{array}$ & $\mathrm{Ca}, \mathrm{Cr}, \mathrm{Er}$ \\
\hline 16 & 32.9 & 503 & 607 & 271 & $\begin{array}{l}\text { Pg-dissacharide (hexose }+ \text { pentose) acylated } \\
\text { with acetic acid }\end{array}$ & $\mathrm{Ca}$ \\
\hline 17 & 33.3 & 503 & 403 & 271 & Pg 3-arabinoside & $\mathrm{Cr}, \mathrm{Tu}$ \\
\hline 18 & 33.5 & n.a. & 535 & 287 & Cy 3-malonylglucoside & $\mathrm{Ca}$ \\
\hline 19 & 35.5 & 504 & 519 & 271 & Pg 3-malonylglucoside & $\mathrm{Ca}, \mathrm{Cr}, \mathrm{Er}, \mathrm{Os}, \mathrm{Tu}$ \\
\hline 20 & 38.4 & n.a. & 563 & 271 & Pg dirhamnoside? & $\mathrm{Ca}, \mathrm{Cr}$ \\
\hline 21 & 39.9 & 504 & 475 & 271 & Pg 3-acetylglucoside & $\mathrm{Ca}, \mathrm{Cr}, \mathrm{Er}, \mathrm{Os}, \mathrm{Tu}$ \\
\hline 22 & 40.6 & 504 & 533 & 271 & $\begin{array}{l}\text { Pg 3-succinylglucoside? Pg 3- } \\
\text { methylmalonylglucoside? }\end{array}$ & Os, Tu \\
\hline 23 & 45.3 & 508 & 503 & 271 & $\begin{array}{l}\text { Pg 3-succinylarabinoside? } \\
\text { Pg malonylrhamnoside? } \\
\text { (Pg 3-methylmalonylarabinoside?) }\end{array}$ & $\mathrm{Ca}, \mathrm{Cr}, \mathrm{Os}, \mathrm{Tu}$ \\
\hline 24 & 46.2 & n.a. & 549 & 287 & $\begin{array}{l}\text { Cy 3-succinylglucoside? } \\
\text { Cy malylrhamnoside? } \\
\text { (Cy 3-methylmalonylglucoside?) }\end{array}$ & $\mathrm{Ca}, \mathrm{Tu}$ \\
\hline 25 & 47.1 & n.a. & 517 & 271 & $\begin{array}{l}\text { Pg 3-diacetylglucoside? } \\
\text { (Pg succinylrhamnoside?) } \\
\text { (Pg 3-methylmalonylrhamnoside?) }\end{array}$ & $\mathrm{Ca}, \mathrm{Cr}, \mathrm{Tu}$ \\
\hline
\end{tabular}

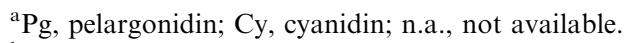

${ }^{\mathrm{b}} \mathrm{Ca}$, Camarosa; Cr, Carisma; Er, Eris; Os, Oso Grande; Tu, Tudnew.

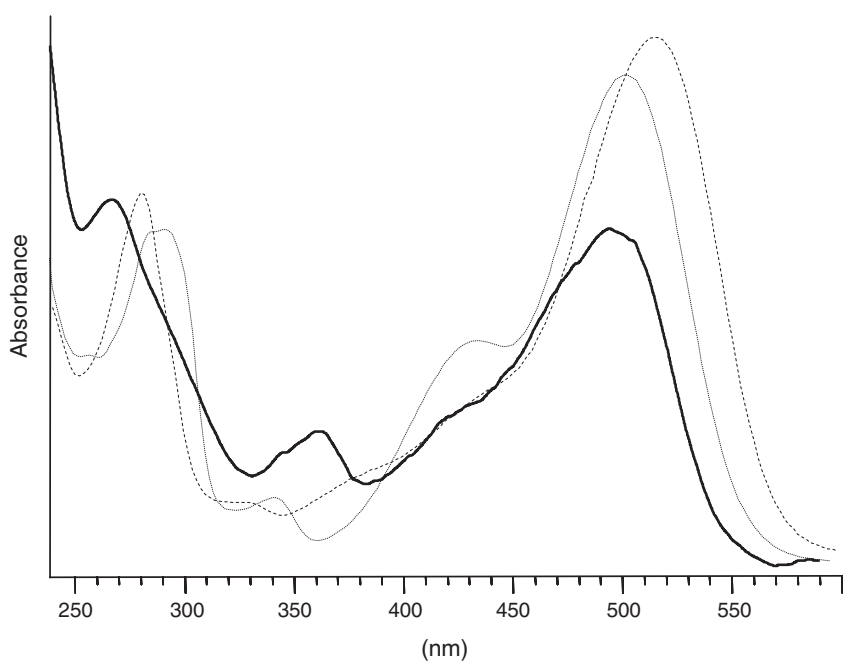

Fig. 3. UV-vis spectra of pelargonidin 3-glucoside (-), cyanidin 3-glucoside (-- - ) and peak 11 (5-carboxypyranopelargonidin 3-glucoside) (-) recorded with the HPLC diode array detector. 3-malonylglucoside (peak 18) was also detected in our samples, as a very small peak in the chromatograms of cv. Camarosa. It was assigned according to its mass (molecular ion at $m / z 535, \mathrm{MS}^{2}$ fragment at $m / z$ 287) and HPLC retention characteristics, eluting immediately before Pg 3malonylglucoside. Further confirmation of the identity of compounds 18 and 19 was provided for comparison of their chromatographic and absorption and mass spectral characteristics with those of Cy 3-(6"-malonylglucoside) and Pg 3-(6"-malonylglucoside) previously identified in our laboratory in purple corn (de Pascual-Teresa, SantosBuelga, \& Rivas-Gonzalo, 2002) and available in our anthocyanin library. In our knowledge, Cy 3-malonylglucoside had not been previously reported in strawberry.

Compounds 1-4 were assigned to condensed pigments containing $\mathrm{C}-\mathrm{C}$ linked anthocyanin $(\mathrm{Pg})$ and flavanol (catechin or afzelechin) residues (Fig. 1c), as discussed elsewhere (González-Paramás et al., 2005). Pigments with the same structural characteristics as compounds $1-3$ were 
isolated from strawberry and fully characterised using NMR by Fossen et al. (2004). Compound 4 (i.e. (epi)afzelechin-(4 $\rightarrow 8)$-Pg 3-rut) was not reported by those authors, but firstly described by our group (González-Paramás et al., 2005).

Anthocyanins 7, 8, 9, 13, 15 and 16 have been previously detected and tentatively identified in strawberries from cv. Camarosa by our group (Lopes-da-Silva et al., 2002). They correspond to: Pg-3,5-digluc (peak 7), Cy 3-rutinoside (8), Cy 3-malonylglucosyl-5-glucoside (9), Pg 3-malylglucoside (13) and two Pg biosides acylated with acetic acid (15 and 16).

Peak 17 was only relevant in the samples of cv. Carisma. The molecular ion at $m / z$ 403, releasing an $\mathrm{MS}^{2}$ fragment at $m / z 271(\mathrm{Pg})$, is consistent with a $\mathrm{Pg}$ pentoside. Arabinose and xylose are the most common pentose substituents in anthocyanins (Mazza \& Miniati, 1993). No actual identification can be made of the sugar residue from the MS spectrum, but Pg 3-arabinoside was reported by some authors (Fiorini, 1995; Goiffon et al., 1999) as the third major anthocyanin in some strawberry varieties. For that reason and since no other pentoside was detected in our samples, peak 17 was tentatively assigned to Pg 3arabinoside.

Bakker et al. (1994) detected in some strawberry cultivars two pigments whose masses, obtained by FABMS, were coherent with the succinyl derivatives of Pg 3gluc and Cy 3-gluc. Molecular ions that may correspond to these two anthocyanins were also detected in our samples for peaks $22(\mathrm{~m} / \mathrm{z}$ at 533$)$ and $24(\mathrm{~m} / \mathrm{z}$ at 549$)$, respectively. However, their identity causes some doubt since Cy succinylglucoside should be expected to elute before the corresponding Pg succinylglucoside. A theoretical possibility that would also match these molecular ions is that one or both of them are products derived from anthocyanins acylated with malonic acid by esterification of the free carboxyl unit of the malonyl residue with the methanol used as a solvent for the extraction. Similar reaction was previously demonstrated in our lab to occur in anthocyanins of purple corn (de Pascual-Teresa et al., 2002), where the formation of ethyl derivatives of the malonylglucosides of cyanidin, peonidin and pelargonidin was observed following esterification with ethanol. Even if in that study the process was induced by heating $\left(60^{\circ} \mathrm{C}\right)$, methylation should not be discarded in our strawberry samples. In support of that possibility is the fact that peak 22 is particularly noticeable in the extracts of cv. Tudnew, where its potential precursor, Pg 3-malonylglucoside (peak 19), is in relatively higher amounts than in the rest of strawberry varieties analysed.

Similarly, peak 24 might be the corresponding methyl derivative of $\mathrm{Cy} 3$-malonylglucoside, although in this case the reduced levels of the precursor anthocyanin (i.e. peak 18) would not support it. Another structure that also matches the molecular ion of peak 24 is that of a $\mathrm{Cy}$ malylrhamnoside. Nevertheless, such identity is much more uncertain taking into account that the corresponding non- acylated Cy rhamnoside, that would have also been expected to occur in the samples, was not detected.

The molecular ion of peak $23(\mathrm{~m} / z$ at 503) would match either a Pg succinylpentoside or a Pg malonylrhamnoside. The facts that peak 23 appeared in the same samples as peak 17 (assigned to $\mathrm{Pg}$ 3-arabinoside) and that $\mathrm{Pg}$ rhamnoside was not detected in any sample, seem to support the first identity (i.e. Pg succinylpentoside).

Different possible structures can also be suggested for peak 25, whose molecular ion at $\mathrm{m} / z 517$ would match either a diacetyl derivative of Pg 3-gluc, a Pg succinylrhamnoside or a Pg methylmalonylrhamnoside. All of them would be in agreement with its late elution. Newly, the fact that no Pg rhamnoside was detected might support the first identity. Curiously, peak 20 showed a molecular ion $(\mathrm{m} / \mathrm{z}$ at 563$)$ that coincides with that of a Pg aglycone bearing two rhamnose substituents, identity that would also agree with its lower polarity when compared to Pg 3gluc and Pg 3-rut. As for peaks 23 and 25, the nondetection of a Pg monorhamnoside would raise some doubt about the dirhamnosyl nature of peak 20 .

The possibility that any of the peaks 20,23 or 25 contain a $p$-coumaroyl acyl residue instead of a rhamnose was discarded. No shoulder at $310-330 \mathrm{~nm}$ was observed in the absorption spectra of any of the anthocyanins detected in the samples analysed, thus indicating that no hydroxycinnamic acids but only aliphatic acids are involved in acylation of strawberry anthocyanins.

Finally, three other minor pigments (peaks 6,11 and 14) were also detected in some samples. Mass characteristics of peak 6 correspond to a Pg hexoside (molecular ion at $\mathrm{m} / \mathrm{z}$ 433 MS $^{2}$ fragment at $m / z$ 271). Taking into account that galactose is the only relevant hexose found in anthocyanins besides glucose (Mazza \& Miniati, 1993) and the retention characteristics of the peak, eluting before Pg 3-glucoside, it was tentatively associated to Pg 3-galactoside (galactosides elute before the equivalent glucosides; Escribano-Bailón, Santos-Buelga, Alonso, \& Salinas, 2002). Peak 11 showed a molecular ion at $m / z 501$ that released an $\mathrm{MS}^{2}$ fragment at $m / z 339$ (-162 amu, loss of a glucose moiety) and a characteristic UV-vis spectrum (Fig. 3) with $\lambda_{\max }$ in the visible region at $492 \mathrm{~nm}$, hypsochromically shifted with regard to that of $\mathrm{Pg}$, and an additional maximum at $335 \mathrm{~nm}$. These mass and spectral features allowed assignment as 5-carboxypyranopelargonidin 3-glucoside (Fig. 1b), a pigment recently identified in strawberry by Andersen et al. (2004). Such a structure is similar to that of the pyruvic acid adducts of anthocyanins formed in red wines during winemaking and ageing (Mateus, de PascualTeresa, Rivas-Gonzalo, Santos-Buelga, \& de Freitas, 2002)

Mass spectrum of peak 14 (Fig. 4) revealed a molecular ion at $m / z 422$ that released a unique $\mathrm{MS}^{2}$ fragment at $\mathrm{m} / \mathrm{z}$ 331, a mass that might correspond to the anthocyanidin malvidin $(\mathrm{Mv})$. However, the small difference of mass between the molecular ion and the $\mathrm{MS}^{2}$ fragment (92 amu) does not allow identification of the peak as a $\mathrm{Mv}$ glycoside; 

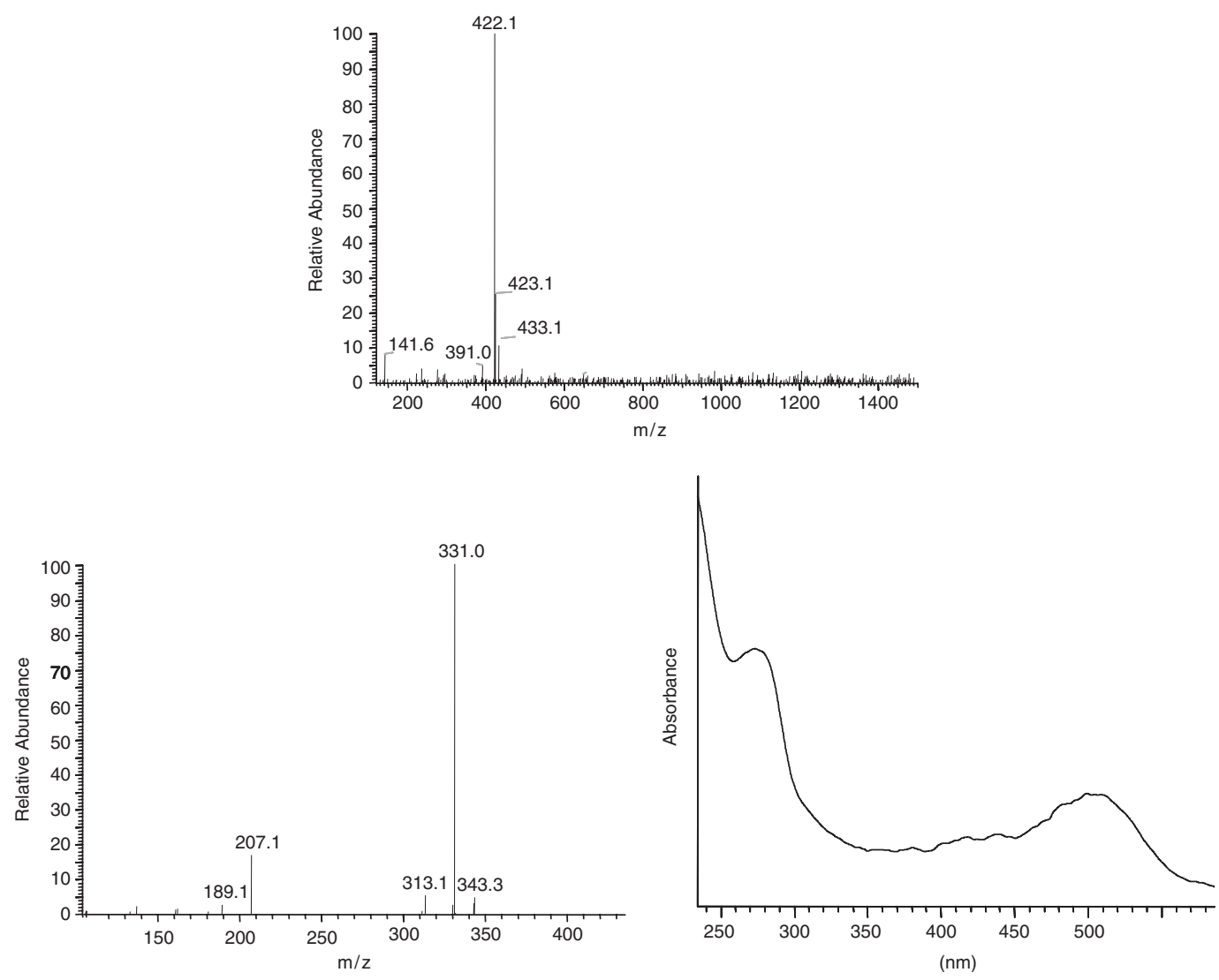

Fig. 4. Mass (molecular ion and $\mathrm{MS}^{2}$ ) and UV-vis spectra of peak 14 recorded with the HPLC diode array detector.

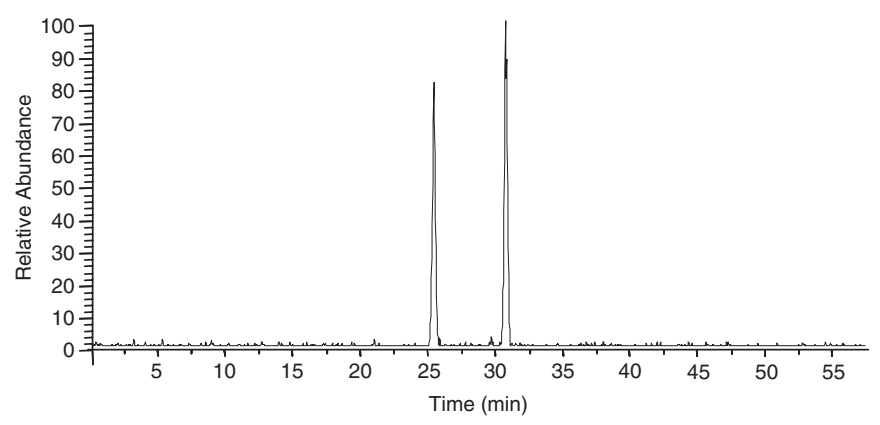

Fig. 5. Ion chromatogram extracted for $m / z 422$ corresponding to a strawberry extract from cv. Tudnew.

on the other hand, the even molecular ion $(\mathrm{m} / \mathrm{z}$ 422) may suggest that the lost fragment contains $\mathrm{N}$ or $\mathrm{S}$. Furthermore, another compound with the same mass characteristics (molecular ion at $\mathrm{m} / \mathrm{z} 422$ and $\mathrm{MS}^{2}$ fragment at $\mathrm{m} / \mathrm{z}$ 331) was found in the same strawberry samples when a search was made in the mass chromatograms (Fig. 5), pointing out that two isomeric structures of the compound exist. The peak of the second compound is overlapped by that of Pg 3-rutinoside and for that reason it was not detected in the DAD chromatograms. Mass characteristics of peak 14 are quite unusual for an anthocyanin, although its UV-vis spectrum (Fig. 4) is in support of its anthocyanin nature. In any case, $\lambda_{\max }$ in the visible region $(504 \mathrm{~nm})$ is not characteristic of a $\mathrm{Mv}$-derived anthocyanin $\left(\lambda_{\max }\right.$ $525-530 \mathrm{~nm}$ ) but rather of a Pg-derived or a C-4substituted anthocyanin. Thus, the existence of malvidin as anthocyanidin in compound 14 is doubtful and no definitive structure could be matched with its spectral and mass features.

\subsection{Content and distribution of anthocyanins}

Table 2 shows the individual concentrations of the three major anthocyanins (i.e. Cy 3-gluc, Pg 3-gluc, Pg 3-rut) in the extracts of the five strawberry varieties in the two harvests analysed. Total anthocyanins would range between 200 and $600 \mathrm{~m} \mathrm{~kg}^{-1}$ fresh weight. In general, these anthocyanin contents are roughly similar to those reported by other authors. Values of total anthocyanins ranging $150-350 \mathrm{mg} \mathrm{kg}^{-1}$ were collected by Clifford (2000) from the literature.

In our study notable variability was found among samples of each variety and year, suggesting that edaphic-climatic factors and degree of maturity have a strong influence on the anthocyanin levels. Nevertheless, some influence of the strawberry cultivar may also exist. Meyers, Watkins, Pritts, and Hai-Liu (2003), in a study carried out with eight different strawberry varieties, reported average concentrations of $414 \mathrm{mg} \mathrm{kg}^{-1}$, with strong differences among cultivars, the richest one 
Table 2

Anthocyanin contents in samples from five strawberry cultivars harvested in 2001 and 2002

\begin{tabular}{lllll}
\hline & & Cy 3-gluc & Pg 3-gluc & Pg 3-rut \\
\hline Camarosa & 2001 & $25 \pm 6$ & $261 \pm 36$ & $43 \pm 7$ \\
\multirow{2}{*}{ Carisma } & 2002 & $41 \pm 13$ & $384 \pm 88$ & $55 \pm 9$ \\
\multirow{2}{*}{ Eris } & 2001 & $10 \pm 3$ & $242 \pm 49$ & $15 \pm 5$ \\
\multirow{2}{*}{ Oso Grande } & 2002 & $13 \pm 5$ & $314 \pm 112$ & $24 \pm 4$ \\
\multirow{2}{*}{ Tudnew } & 2001 & $27 \pm 8$ & $185 \pm 66$ & $13 \pm 5$ \\
& 2002 & $23 \pm 4$ & $163 \pm 22$ & $14 \pm 3$ \\
& 2001 & $24 \pm 3$ & $289 \pm 34$ & $29 \pm 2$ \\
& 2001 & $11 \pm 1$ & $162 \pm 6$ & $16 \pm 2$ \\
& 2002 & $28 \pm 4$ & $468 \pm 124$ & $33 \pm 13$ \\
\end{tabular}

Concentrations (mean \pm s.d.; $n=3$ ) are in fresh weight.

${ }^{\text {a }}$ Expressed as mg Cy 3-gluc. $\mathrm{kg}^{-1}$.

${ }^{\mathrm{b}}$ Expressed as mg Pg 3-gluc. $\mathrm{kg}^{-1}$.

(Earliglow) having twice the concentration than the poorest (Allstar). None of the varieties studied by those authors coincides with the ones analysed by us. Concentrations of $185.0 \pm 15.0$ and $840.2 \pm 5.7 \mathrm{mg} \mathrm{kg}^{-1}$ were determined in samples of Oso Grande and Camarosa, respectively, by Garcia-Viguera, Zafrilla, and Tomas-Barberan (1998). The high levels found in Camarosa by those authors were explained by the more intense pigmentation of the inner tissues of the fruit than found in other varieties. Such differences were also observed in the Camarosa samples here analysed, as well as in those of cv. Tudnew, varieties that showed the highest concentrations among those studied. By contrast, the faintest inner pigmentation and the lowest concentrations were observed in the samples of cv. Eris. Anthocyanin content in Camarosa strawberries was also determined by Castro, Gonçalves, Teixeira, and Vicente (2002) obtaining values closer to those found in our samples $\left(482 \pm 14 \mathrm{mg} \mathrm{kg}^{-1}\right)$. It should also be taken into account that differences in concentration found for a same variety by different authors might also be due to the use of different extraction solvents.

Regarding anthocyanin distribution, Pg 3-gluc is the predominant compound in the strawberry extracts $(83 \%$ of total anthocyanins on average), usually followed by Pg 3rut $(8 \%)$ and $\mathrm{Cy} 3$-gluc $(7 \%)$. Percentages of $89-95 \%$ for Pg 3-gluc and 4-11\% for Cy 3-gluc were found by Goiffon et al. (1999) in a study carried out with five strawberry varieties different to those analysed by us. Curiously, this author does not report the presence of Pg 3-rut, but indicates Pg 3-arabinoside to be the third anthocyanin in the varieties Senga sengana and El santa.

In our study, the samples of Camarosa were those with lower percentages of Pg 3-gluc (77-78\%) and the highest ones of Pg 3-rut (11-13\%), whilst samples of Carisma possessed the highest proportions of Pg 3-gluc (88-89\%) and the lowest ones of Cy 3-gluc (3-4\%). Eris was the only variety that showed greater levels of $\mathrm{Cy} 3$-gluc $(12 \%)$ than Pg 3-rut (6-7\%). The proportions found among these three anthocyanins were fairly consistent for the different samples of the same variety (Table 2), suggesting a characteristic anthocyanin distribution. A similar conclusion was obtained by Garcia-Viguera et al. (1998) who also found similar proportions to us in cv. Camarosa and Oso Grande.

According to Tamura et al. (1995) Pg 3-malonylglucoside is one of the main anthocyanins in strawberry comprising $30 \%, 25 \%$, and $12 \%$ of the total anthocyanin content in cv's Nyoho, Himesodachi and Reiko, respectively. Proportions between $5 \%$ and $24 \%$ of this anthocyanin are also determined by Yoshida et al. (2002) in 11 Japanese strawberry cultivars. In our case, no important levels of acylated anthocyanins were found in the samples analysed. The highest percentages were determined in the extracts of cv. Tudnew where Pg 3-malonylglucoside and Pg 3 -acetylglucoside represented about $1 \%$ of total anthocyanins. At this respect, it is pertinent to indicate that extraction with solvents containing $\mathrm{HCl}$ may result in pigment degradation due to the concentration of $\mathrm{HCl}$, and this is one of the reasons why anthocyanins containing labile aliphatic acyl moieties may have been overlooked (Strack \& Way, 1989). In assays carried out in our laboratory with grape anthocyanins no relevant decrease in the levels of anthocyanins acylated with acetic acid was observed when $0.1 \% \mathrm{HCl}$ in methanol was used for extraction, as in the present study. We found that a critical point, even when low $\mathrm{HCl}$ percentages are used, is the evaporation phase, where an increase in the concentration of $\mathrm{HCl}$ is produced as a result of the removal of the organic solvent. For that reason, in this study, water was added prior to solvent evaporation to prevent the increase in the concentration of $\mathrm{HCl}$ during evaporation. In spite of this, some cleavage of the aliphatic acyl residues cannot be discarded with subsequent underestimation of the corresponding acylated anthocyanins.

\section{Conclusions}

The use of optimized HPLC conditions coupled to diode array and mass detection allowed us to detect up to 25 different anthocyanin pigments in strawberry fruits from five different varieties (cv. Eris, Oso Grande, Carisma, Tudnew and Camarosa). Most anthocyanins showed Pg as aglycone, although some Cy derivatives were also present. Glucose was the most usual substituting sugar, but rutinose and possibly arabinose and rhamnose have been found, as well as acylation with different aliphatic acids (e.g. malic, malonic, succinic or acetic acids). A relevant aspect was the confirmation in the strawberry fruits of the presence of anthocyanin-derived pigments, namely a Pg-derived pyranoanthocyanin and four condensed products containing $\mathrm{C}-\mathrm{C}$ linked anthocyanin $(\mathrm{Pg})$ and flavanol (catechin and afzelechin) residues, whose detection in natural plant sources was very recently made. Up to then, this type of compounds was associated with reactions taking place during processing and ageing of red wines. In the five 
strawberry varieties studied, $\mathrm{Pg} 3$-gluc is always the predominant anthocyanin, usually followed by Pg 3-rut and $\mathrm{Cy} 3$-gluc. These three compounds represented more than $95 \%$ of total anthocyanins in strawberry. Tudnew and Camarosa were the varieties with the higher anthocyanin content among those analysed.

\section{Acknowledgements}

Financial support of Junta de Castilla y León (Spain) through the grant ref. SA086/01 is greatly acknowledged. Author Lopes da Silva was funded by European Union and Government of Portugal through the Programme PRODEP III (2001-2003). Strawberry samples were kindly provided by Dr. Luis Carlos Sanz Martinez, Scientific Researcher at Instituto de la Grasa-CSIC in Seville (Spain).

\section{References}

Andersen, Ø. M., Fossen, T., Torskangerpoll, K., Fossen, A., \& Hauge, U. (2004). Anthocyanin from strawberry (Fragaria ananassa) with the novel aglycone, 5-carboxypyranopelargonidin. Phytochemistry, 65, 405-410.

Bakker, J., Bridle, P., \& Bellworthy, S. J. (1994). Strawberry juice colour: a study of the quantitative and qualitative pigment composition of juices from 39 genotypes. Journal of the Science of Food and Agriculture, 64, 31-37.

Bridle, P., \& Garcia-Viguera, C. (1997). Analysis of anthocyanins in strawberries and elderberries. A comparison of capillary zone electrophoresis and HPLC. Food Chemistry, 59, 299-304.

Castro, I., Gonçalves, O., Teixeira, J. A., \& Vicente, A. A. (2002). Comparative study of a Selva and Camarosa strawberries from the commercial market. Journal of Food Science, 67, 2132-2137.

Clifford, M. N. (2000). Anthocyanins: nature, occurrence and dietary burden. Journal of the Science of Food and Agriculture, 80, 1063-1072.

Co, H., \& Markakis, P. (1968). Flavonoid compounds in strawberry fruits. Journal of Food Science, 33, 281-283.

de Pascual-Teresa, S., Santos-Buelga, C., \& Rivas-Gonzalo, J. C. (2002). LC-MS analysis of anthocyanins from purple corn cob. Journal of the Science of Food and Agriculture, 82, 1003-1006.

Escribano-Bailón, M. T., Santos-Buelga, C., Alonso, G. L., \& Salinas, M. R. (2002). Anthocyanin composition of Coriaria myrtifolia L. fruit. Phytochemical Analysis, 13, 354-357.

Fiorini, M. (1995). Preparative high-performance liquid chromatography for the purification of natural anthocyanins. Journal of Chromatography A, 692, 213-219.

Fossen, T., Rayyan, S., \& Andersen, Ø. M. (2004). Dimeric anthocyanins from strawberry (Fragaria ananassa) consisting of pelargonidin 3glucoside covalently linked to four flavan-3-ols. Phytochemistry, 65, 1421-1428.

Garcia-Viguera, C., Zafrilla, P., \& Tomas-Barberan, F. T. (1998). The use of acetone as an extraction solvent for anthocyanins from strawberry fruits. Phytochemical Analysis, 9, 274-277.

Goiffon, J. P., Mouly, P. P., \& Gaydou, E. M. (1999). Anthocyanic pigment determination in red fruit juices, concentrated juices and syrups using liquid chromatography. Analytica Chimica Acta, 382, $39-50$.

González-Paramás, A. M., Lopes da Silva, F., Martín-López, P., MaczPop, G., González-Manzano, S., Alcalde-Eon, C., Pérez-Alonso, J. J., et al. (2005). Flavanol-anthocyanin condensed pigments in natural plant sources. Food Chemistry Available online since 16/02/2005.

Hebrero, E., Santos-Buelga, C., \& Rivas-Gonzalo, J. C. (1988). HPLCDAS identification of anthocyanins of Vitis vinifera variety Tempranillo. American Journal of Enology and Viticulture, 39, 227-233.

Heinonen, I. M., Meyer, A. S., \& Frankel, E. N. (1998). Antioxidant activity of berry phenolics on human low-density lipoprotein and liposome oxidation. Journal of Agricultural and Food Chemistry, 46, 4107-4112.

Hong, V., \& Wrolstad, R. E. (1990a). Characterization of anthocyanincontaining colorants in fruit juices by HPLC-photodiode array detection. Journal of Agricultural and Food Chemistry, 38, 698-707.

Hong, V., \& Wrolstad, R. E. (1990b). Use of HPLC separation/ photodiode array detection for characterization of anthocyanins. Journal of Agricultural and Food Chemistry, 38, 708-715.

Jurd, L. (1969). Review of polyphenol condensation reactions and their possible occurrence in the aging of wines. American Journal of Enology and Viticulture, 20, 191-195.

Lopes-da-Silva, F., de Pascual-Teresa, S., Rivas-Gonzalo, J. C., \& SantosBuelga, C. (2002). Identification of anthocyanin pigments in strawberry ( $c v$ Camarosa) by LC using DAD and ESI-MS detection. European Food Research and Technology, 214, 248-253.

Lukton, A., Chichester, C. O., \& MacKiney, G. (1955). Characterization of a second pigment in strawberries. Nature, 176, 790.

Mateus, N., de Pascual-Teresa, S., Rivas-Gonzalo, J., Santos-Buelga, C., \& de Freitas, V. (2002). Structural diversity of anthocyanin-derived pigments in port wines. Food Chemistry, 76, 335-342.

Mazza, G., \& Miniati, E. (1993). Anthocyanins in fruits, vegetables and grains. Boca Raton, FL: CRC Press Inc.

Meyers, K. J., Watkins, C. B., Pritts, M. P., \& Hai-Liu, R. (2003). Antioxidant and antiproliferative activities of strawberries. Journal of Agricultural and Food Chemistry, 51, 6887-6892.

Robinson, G. M., \& Robinson, M. A. (1931). Survey of anthocyanins I. Biochemical Journal, 25, 1687-1705.

Salas, E., Atanasova, V., Poncet-Legrand, C., Meudec, E., Mazauric, J. P., \& Cheynier, V. (2004). Demonstration of the occurrence of flavanol-anthocyanin adducts in wine and model solutions. Analytica Chimica Acta, 513, 325-332.

Somers, T. C. (1971). The polymeric nature of wine pigments. Phytochemistry, 10, 2175-2186.

Strack, D., \& Way, V. (1989). Anthocyanins. In J. B. Harborne (Ed.), Methods in Plant Biochemistry, Vol. I (pp. 325-356). New York: Academic Press.

Tamura, H., Takada, M., \& Yoshida, Y. (1995). Pelargonidin 3-O-(6-Omalonyl- $\beta$ - $D$-glucopyranoside) in Fragaria $x$ ananassa Duch cv Nyoho. Bioscience, Biotechnology and Biochemistry, 59, 1157-1158.

Vivar-Quintana, A. M., Santos-Buelga, C., Francia-Aricha, E., \& RivasGonzalo, J. C. (1999). Formation of anthocyanin-derived pigments in experimental red wines. Food Science and Technology International, 5, $347-352$.

Wang, S. Y., \& Jiao, H. (2000). Scavenging capacity of berry crops on superoxide radicals, hydrogen peroxide, hydroxyl radicals and singlet oxygen. Journal of Agricultural and Food Chemistry, 48, 5677-5684.

Wang, S. Y., \& Lin, H. S. (2000). Antioxidant activity in fruits and leaves of blackberry, raspberry and strawberry varies with cultivar and developmental stage. Journal of Agricultural and Food Chemistry, 48, 140-146.

Yoshida, Y., Koyama, N., \& Tamura, H. (2002). Color and anthocyanin composition of strawberry fruit: changes during fruit development and differences among cultivars, with special reference to the occurrence of pelargonidin 3-malonylglucoside. Journal of the Japanese Society for Horticultural Science, 71, 355-361. 